J. Dairy Sci. 98:1321-1324

http://dx.doi.org/10.3168/jds.2014-8267

(c) American Dairy Science Association ${ }^{\circledR}, 2015$.

\title{
Short communication: Genetic parameters for fertility-related disorders in Norwegian Red
}

\author{
Katrine Haugaard ${ }^{* 1}$ and Bjørg Heringstad ${ }^{*} \dagger$ \\ *Department of Animal and Aquacultural Sciences, Norwegian University of Life Sciences, PO Box 5003, 1432 Ås, Norway \\ †GENO Breeding and Al Association, PO Box 5003, 1432 Ås, Norway
}

\begin{abstract}
Heritabilities and genetic correlations were estimated for the 4 most common fertility-related disorders in Norwegian Red: retained placenta, cystic ovaries, silent heat, and metritis. Data on 1,747,500 lactations from 780,114 cows calving from January 2001 through December 2011 were analyzed using multivariate threshold sire models to estimate variance components for the 4 disorders in the first 5 lactations. The traits were defined as binary within lactation $(0=$ unaffected, $1=$ affected), and each fertility-related disorder was analyzed separately with the 5 lactations as correlated traits. The mean frequency of affected cows ranged from 0.5 to $1.7 \%$ for cystic ovaries, 0.7 to $1.1 \%$ for metritis, 1.3 to $3.4 \%$ for retained placenta, and 1.7 to $2.7 \%$ for silent heat. Posterior means (standard deviations) of heritability of liability ranged from 0.02 (0.01) to 0.12 (0.01), and were lowest for silent heat and highest for cystic ovaries. Genetic correlations across lactation within disorder were positive and moderate to high, ranging from 0.79 to 0.95 for cystic ovaries, 0.40 to 0.75 for metritis, 0.53 to 0.94 for retained placenta, and 0.39 to 0.83 for silent heat.
\end{abstract}

Key words: retained placenta, cystic ovaries, silent heat, metritis, genetic correlation

\section{Short Communication}

Fertility-related disorders can decrease cow fertility and increase the calving interval, and they are of economic importance due to increased labor and veterinary costs and reduced production. Cystic ovaries (CO), metritis (MET), retained placenta (RP), and silent heat $(\mathbf{S H})$ are the most common fertility-related disorders in Norway, and this category of diseases was the only category that increased in frequency in Norway in 2013 (Norwegian Cattle Health Services, 2014). Like many other disease traits, heritabilities of fertility-

Received April 22, 2014.

Accepted November 4, 2014.

${ }^{1}$ Corresponding author: katrine.haugaard@nmbu.no related disorders are generally low. Heritability estimates from threshold models range from 0.05 to 0.08 for CO and 0.03 to 0.08 for MET (Zwald et al., 2004; Heringstad, 2010; Koeck et al., 2010), 0.06 to 0.08 for RP (Heringstad et al., 2005; Heringstad, 2010; Koeck et al., 2010), and 0.01 to 0.06 for SH (Heringstad, 2010; Koeck et al., 2010). Studies have shown that heritability varies between lactations; for example, Zwald et al. (2004) reported larger heritability estimates for CO and MET from the first lactation relative to estimates from all available lactations. Heringstad et al. (2005) reported a heritability of 0.08 for RP in lactations 1 to 3 in Norwegian Red, but the genetic correlations between lactations ranged from 0.55 to 0.65 , indicating that the disorder genetically is not the same trait across lactations.

As some of the fertility-related disorders increase in frequency in the later lactations, it may be advantageous to use multiple lactations in genetic evaluations. The aims were to estimate heritabilities for CO, MET, $\mathrm{RP}$, and $\mathrm{SH}$ in the first 5 lactations, and to evaluate whether these disorders can be considered to be genetically the same trait across lactations based on genetic correlations between the lactations within each disorder.

Information on calving and fertility-related health records were extracted from the Norwegian Dairy Herd Recording System. Information included up to 5 lactations from 780,114 cows sired by Norwegian Red AI bulls, calving from January 2001 to December 2011. Cows without first-lactation data were omitted from the data set. Age at calving had to be within defined intervals for the lactation record to be included (20-36 mo, 32-48 mo, 44-60 mo, 56-72 mo, and 68-84 mo for lactations 1 to 5 , respectively). The definition of lactation was from the day of calving until $15 \mathrm{~d}$ before the next calving, culling, or $400 \mathrm{~d}$ after calving, whichever occurred first. The data set contained 20 traits, 5 lactations for each of the 4 disorders, where each trait was defined as a binary $(0=$ unaffected, $1=$ affected $)$. For $\mathrm{RP}$, the veterinary treatment had to occur within the first $5 \mathrm{~d}$ after calving, whereas for the other disorders all health records within the defined lactation were 
Table 1. Number of records and mean frequency of cystic ovaries $(\mathrm{CO})$, metritis (MET), retained placenta $(\mathrm{RP})$, and silent heat $(\mathrm{SH})$ in lactations 1 to 5 for Norwegian Red

\begin{tabular}{|c|c|c|c|c|c|}
\hline \multirow{2}{*}{$\begin{array}{l}\text { Lactation } \\
\text { no. }\end{array}$} & \multirow{2}{*}{$\begin{array}{l}\text { No. of } \\
\text { records }\end{array}$} & \multicolumn{4}{|c|}{ Frequency (\%) } \\
\hline & & $\mathrm{CO}$ & MET & $\mathrm{RP}$ & $\mathrm{SH}$ \\
\hline 1 & 780,114 & 0.5 & 0.7 & 1.3 & 2.7 \\
\hline 2 & 489.903 & 1.0 & 0.6 & 2.1 & 2.1 \\
\hline 3 & 280,085 & 1.5 & 0.7 & 2.6 & 2.0 \\
\hline 4 & 138,938 & 1.6 & 0.8 & 3.1 & 1.8 \\
\hline 5 & 58,461 & 1.7 & 1.1 & 3.4 & 1.7 \\
\hline
\end{tabular}

used. Numbers of records and mean frequency for the traits are given in Table 1 . In total, 27,185 animals were in the pedigree file, which consisted of the 1,247 bulls with daughters in the data set and their dams and sires traced back as far as possible.

Each of the 4 fertility-related disorders was analyzed separately, with the 5 lactations as correlated traits in a multivariate threshold sire model. In matrix notation, the model can be written as $\boldsymbol{\lambda}=\mathbf{X} \boldsymbol{\beta}+\mathbf{Z}_{\mathrm{h}} \mathbf{h}+\mathbf{Z}_{\mathrm{s}} \mathbf{s}+$ $\mathbf{e}$, where $\boldsymbol{\lambda}$ is a vector of unobserved liabilities, $\boldsymbol{\beta}$ is a vector of systematic effects (described below), $\mathbf{h}$ is a vector of random herd-5-year effects (30,583 levels), s is the random effect of sire $(1,247$ levels $)$, $\mathbf{e}$ is the vector of residual, and $\mathbf{X}, \mathbf{Z}_{\mathrm{h}}$, and $\mathbf{Z}_{\mathrm{s}}$ are the corresponding incidence matrices. The systematic effects were yearseason of calving (seasons defined as January-March, April-June, July-September and October-December) (44, 41, 37, 33 and 29 levels for lactations 1 to 5 respectively) and age at calving in months (17 levels). Herd-5-year classes were defined by using 2 periods of approximately 5 yr each (2001-2006 and 2007-2011). Heritability was calculated as

$$
h^{2}=\frac{4 \sigma_{\text {sire }}^{2}}{\sigma_{\text {sire }}^{2}+\sigma_{\text {herd }}^{2}+\sigma_{\text {residual }}^{2}},
$$

where $\sigma_{\text {sire }}^{2}, \sigma_{\text {herd }}^{2}$, and $\sigma_{\text {residual }}^{2}$ are the sire variance, herd5 -year variance, and residual variance, respectively. A
Bayesian approach using Gibbs sampler in the RJMC routine of the DMU package (Madsen and Jensen, 2007) was used for analyses. Based on Raftery and Lewis convergence statistics using the BOA package (Smith, 2003), we decided to use a total chain length of 300,000 iterations after 10,000-iteration burn-in for all traits.

The mean frequencies were low in all lactations for all disorders, less than $4 \%$ (Table 1). For 2 of the disorders $(\mathrm{CO}$ and $\mathrm{RP})$, frequency increased in later lactations, and for $\mathrm{CO}$ the frequency was 3 times as high in the fifth lactation $(1.7 \%)$ as in the first lactation $(0.5 \%)$. For RP, the frequency more than doubled from the first lactation $(1.3 \%)$ to the fifth lactation $(3.4 \%)$. For MET, the frequency was stable $(0.6-0.8 \%)$ in the first 4 lactations but increased in the fifth lactation (1.1\%). The frequency of $\mathrm{SH}$ decreased with increasing lactations, from 2.7 to $1.7 \%$. In general, these frequencies were lower than disease frequencies reported in other studies; for $\mathrm{CO}$, frequencies range from $3.1 \%$ (Canadian Holstein, van Dorp et al., 1998) to 13\% (Finnish Ayrshire, Mäntysaari et al., 1993), whereas for MET they range from 2.5\% (Finnish Ayrshire, Pösö and Mäntysaari, 1996) to 21\% (US Holstein, Zwald et al., 2004). Koeck et al. (2010) reported a frequency for SH of $6.3 \%$ in Austrian Fleckvieh. For RP, the frequencies were more similar to those presented in the present study, where most range between $1.3 \%$ (Canadian Holstein, van Dorp et al., 1998) and 5.8\% (Austrian Simmental, Schnitzenlehner et al., 1998), although Lin et al. (1989) presented frequencies for RP in US Holstein of 8.5 and $12.7 \%$ for second-lactation cows and older cows, respectively

Heritabilities of liability were low for all traits (Tables 2, 3, 4, and 5). The posterior mean ranged from 0.02 ( $\mathrm{SH} 2$ and $\mathrm{SH} 3$; where $\mathrm{SH} 2=\mathrm{SH}$ in lactation 2) to 0.12 (CO2), with small SD (0.01-0.02) for all traits, indicating accurate heritability estimates. All first-lactation estimates were in accordance with those reported by Heringstad (2010), which were based on partly the same data set as in the present study.

Table 2. Posterior mean (SD) of heritability of liability (diagonal), genetic correlations (below diagonal), and herd correlations (above diagonal) for cystic ovaries $(\mathrm{CO} i)$, in 5 lactations $(i=1-5)$, with $95 \%$ highest posterior density interval given in brackets

\begin{tabular}{cccccc}
\hline & $\mathrm{CO} 1$ & $\mathrm{CO} 2$ & $\mathrm{CO} 3$ & $\mathrm{CO} 4$ & $\mathrm{CO} 5$ \\
\hline $\mathrm{CO} 1$ & $0.08(0.01)$ & $0.92(0.02)$ & $0.88(0.03)$ & $0.79(0.03)$ & $0.76(0.05)$ \\
& {$[0.06-0.11]$} & {$[0.89-0.96]$} & {$[0.83-0.93]$} & {$[0.73-0.86]$} & {$[0.66-0.85]$} \\
$\mathrm{CO} 2$ & $0.91(0.04)$ & $0.12(0.01)$ & $0.97(0.01)$ & $0.93(0.02)$ & $0.90(0.02)$ \\
& {$[0.83-0.97]$} & {$[0.09-0.14]$} & {$[0.94-1.00]$} & {$[0.88-0.98]$} & {$[0.83-0.97]$} \\
$\mathrm{CO} 3$ & $0.83(0.06)$ & $0.95(0.02)$ & $0.11(0.01)$ & $0.94(0.03)$ & $0.86(0.04)$ \\
& {$[0.70-0.94]$} & {$[0.90-0.99]$} & {$[0.08-0.14]$} & {$[0.89-0.99]$} & {$[0.78-0.94]$} \\
$\mathrm{CO} 4$ & $0.88(0.06)$ & $0.94(0.03)$ & $0.93(0.04)$ & $0.09(0.02)$ & $0.88(0.05)$ \\
& {$[0.77-0.97]$} & {$[0.89-0.99]$} & {$[0.85-0.99]$} & {$[0.06-0.12]$} & {$[0.80-0.97]$} \\
$\mathrm{CO} 5$ & $0.79(0.09)$ & $0.90(0.07)$ & $0.92(0.06)$ & $0.91(0.06)$ & $0.09(0.02)$ \\
& {$[0.61-0.94]$} & {$[0.77-0.98]$} & {$[0.79-0.99]$} & {$[0.79-0.99]$} & {$[0.06-0.13]$} \\
\hline
\end{tabular}


Table 3. Posterior mean (SD) of heritability of liability (diagonal), genetic correlations (below diagonal), and herd correlations (above diagonal) for metritis (MET $i$ ), in 5 lactations $(i=1-5)$, with $95 \%$ highest posterior density interval given in brackets

\begin{tabular}{lccccc}
\hline & MET1 & MET2 & MET3 & MET4 & MET5 \\
\hline \multirow{2}{*}{ MET1 } & $0.04(0.01)$ & $0.87(0.03)$ & $0.77(0.05)$ & $0.76(0.08)$ & $0.71(0.08)$ \\
& {$[0.02-0.05]$} & {$[0.81-0.93]$} & {$[0.67-0.86]$} & {$[0.61-0.91]$} & {$[0.54-0.86]$} \\
MET2 & $0.57(0.13)$ & $0.03(0.01)$ & $0.85(0.06)$ & $0.82(0.06)$ & $0.86(0.06)$ \\
& {$[0.31-0.81]$} & {$[0.01-0.04]$} & {$[0.75-0.96]$} & {$[0.71-0.94]$} & {$[0.73-0.96]$} \\
MET3 & $0.59(0.15)$ & $0.74(0.13)$ & $0.03(0.01)$ & $0.74(0.08)$ & $0.81(0.07)$ \\
& {$[0.28-0.84]$} & {$[0.50-0.96]$} & {$[0.02-0.05]$} & {$[0.58-0.89]$} & {$[0.66-0.94]$} \\
MET4 & $0.48(0.23)$ & $0.75(0.14)$ & $0.55(0.20)$ & $0.03(0.01)$ & $0.68(0.13)$ \\
& {$[0.07-0.89]$} & {$[0.48-0.95]$} & {$[0.16-0.91]$} & {$[0.01-0.05]$} & {$[0.45-0.92]$} \\
MET5 & $0.72(0.13)$ & $0.47(0.21)$ & $0.42(0.27)$ & $0.40(0.23)$ & $0.06(0.02)$ \\
& {$[0.47-0.93]$} & {$[0.05-0.82]$} & {$[-0.05-0.86]$} & {$[-0.03-0.82]$} & {$[0.02-0.10]$} \\
\hline
\end{tabular}

The highest heritabilities were found for $\mathrm{CO}$, ranging from 0.08 to 0.12 (Table 2), which is in agreement with previously reported heritability estimates for $\mathrm{CO}$ (e.g., Zwald et al., 2004; Koeck et al., 2010). The lowest heritabilities of liability were estimated for SH (0.02-0.04; Table 5) and MET (0.03-0.06; Table 3). Very few studies have published heritability of $\mathrm{SH}$, so comparisons are sparse. Koeck et al. (2010) reported a heritability from a threshold model of 0.012 for $\mathrm{SH}$ and anestrus in the first 5 lactations, which is slightly lower than the estimates reported here. Threshold model heritability estimates for MET range from 0.06 (Koeck et al., 2010) to 0.08 (Zwald et al., 2004), which is in accordance with our estimates. The heritabilities of liability to RP ranged from 0.06 to 0.09 (Table 4). This is in agreement with previous estimates of 0.06 (Koeck et al., 2010) and 0.08 (Heringstad et al., 2005).

Generally, the genetic correlations (Tables 2 to 5) among lactations within each disorder were positive and moderate to high. The highest genetic correlations were found between the CO traits (Table 2), with posterior mean ranging from 0.79 (CO1-CO5) to 0.95 (CO2-CO3), and the upper bounds of the 95\% highest posterior density (HPD) intervals were all $>0.94$. This was higher than genetic correlations of ovulatory disorders between lactations reported previously, ranging from 0.60 to 0.94 (Mäntysaari et al., 1993; Pösö and Mäntysaari, 1996). However, those studies included anestrus, subestrus, and other infertilities in addition to $\mathrm{CO}$, and comparison is therefore difficult.

The posterior means of genetic correlations for $\mathrm{SH}$ ranged from 0.39 (SH1-SH4) to 0.83 (SH3-SH4), whereas for MET, the posterior means of genetic correlations ranged from 0.40 (MET4-MET5) to 0.75 (MET2-MET4). The 95\% HPD intervals for the genetic correlations among these traits were relatively wide, indicating uncertain estimates, especially for the later lactations. For MET5, the 95\% HPD interval of the genetic correlations to MET3 and MET4 even included zero. Previous genetic correlation estimates for MET between lactations range from -0.58 to 0.62 (Mäntysaari et al., 1993; Pösö and Mäntysaari, 1996). In those studies, the standard errors were also large.

The posterior means of genetic correlations for RP showed a difference between the correlations involving the first lactation (0.53-0.69) and the correlations among the second to fifth lactation (0.84-0.94; Table 4). These genetic correlations were slightly higher than those reported by Heringstad et al. (2005), with estimates from 0.55 to 0.65 for RP in the 3 first lactations. Schnitzenlehner et al. (1998) reported a genetic correlation for RP in the first and second lactation of 0.79 , which is higher than the corresponding estimate of the present study.

Table 4. Posterior mean (SD) of heritability of liability (diagonal), genetic correlations (below diagonal), and herd correlations (above diagonal) for retained placenta $(\mathrm{RP} i)$, in 5 lactations $(i=1-5)$, with $95 \%$ highest posterior density interval given in brackets

\begin{tabular}{lccccc}
\hline & RP1 & RP2 & RP3 & RP4 & RP5 \\
\hline RP1 & $0.06(0.01)$ & $0.89(0.03)$ & $0.93(0.03)$ & $0.84(0.04)$ & $0.84(0.05)$ \\
& {$[0.04-0.07]$} & {$[0.84-0.95]$} & {$[0.88-0.98]$} & {$[0.76-0.93]$} & {$[0.74-0.93]$} \\
RP2 & $0.69(0.06)$ & $0.07(0.01)$ & $0.96(0.02)$ & $0.92(0.03)$ & $0.87(0.05)$ \\
& {$[0.56-0.80]$} & {$[0.05-0.08]$} & {$[0.93-0.98]$} & {$[0.86-0.99]$} & {$[0.77-0.96]$} \\
RP3 & $0.60(0.07)$ & $0.92(0.03)$ & $0.08(0.01)$ & $0.92(0.03)$ & $0.88(0.05)$ \\
& {$[0.47-0.74]$} & {$[0.86-0.98]$} & {$[0.06-0.10]$} & {$[0.86-0.98]$} & {$[0.80-0.98]$} \\
RP4 & $0.60(0.08)$ & $0.84(0.05)$ & $0.94(0.03)$ & $0.09(0.01)$ & $0.83(0.06)$ \\
& {$[0.45-0.74]$} & {$[0.74-0.94]$} & {$[0.89-0.99]$} & {$[0.06-0.11]$} & {$[0.70-0.93]$} \\
RP5 & $0.53(0.10)$ & $0.84(0.06)$ & $0.87(0.06)$ & $0.86(0.07)$ & $0.09(0.02)$ \\
& {$[0.32-0.73]$} & {$[0.72-0.95]$} & {$[0.76-0.98]$} & {$[0.73-0.97]$} & {$[0.05-0.12]$} \\
\hline
\end{tabular}


Table 5. Posterior mean (SD) of heritability of liability (diagonal), genetic correlations (below diagonal), and herd correlations (above diagonal) for silent heat $(\mathrm{SH} i)$, in 5 lactations $(i=1-5)$, with $95 \%$ highest posterior density interval given in brackets

\begin{tabular}{lccccc}
\hline & SH1 & SH2 & SH3 & SH4 & SH5 \\
\hline SH1 & $0.04(0.01)$ & $0.96(0.01)$ & $0.93(0.01)$ & $0.90(0.01)$ & $0.88(0.02)$ \\
& {$[0.03-0.05]$} & {$[0.95-0.97]$} & {$[0.92-0.94]$} & {$[0.88-0.93]$} & {$[0.85-0.92]$} \\
SH2 & $0.78(0.06)$ & $0.02(0.01)$ & $0.98(0.01)$ & $0.96(0.01)$ & $0.94(0.02)$ \\
& {$[0.65-0.89]$} & {$[0.02-0.03]$} & {$[0.96-0.99]$} & {$[0.95-0.98]$} & {$[0.91-0.98]$} \\
SH3 & $0.58(0.11)$ & $0.78(0.10)$ & $0.02(0.01)$ & $0.98(0.01)$ & $0.97(0.02)$ \\
& {$[0.37-0.78]$} & {$[0.59-0.97]$} & {$[0.01-0.03]$} & {$[0.96-1.00]$} & {$[0.93-1.00]$} \\
SH4 & $0.39(0.14)$ & $0.64(0.11)$ & $0.83(0.09)$ & $0.03(0.01)$ & $0.96(0.02)$ \\
& {$[0.13-0.64]$} & {$[0.42-0.87]$} & {$[0.95-0.98]$} & {$[0.01-0.04]$} & {$[0.93-0.99]$} \\
SH5 & $0.45(0.18)$ & $0.54(0.20)$ & $0.51(0.22)$ & $0.47(0.18)$ & $0.04(0.02)$ \\
& {$[0.14-0.82]$} & {$[0.16-0.92]$} & {$[0.10-0.88]$} & {$[0.11-0.81]$} & {$[0.01-0.08]$} \\
\hline
\end{tabular}

The posterior means of herd correlations between lactations were positive and high (0.71-0.98) for all the fertility-related disorders (Tables 2 to 5 ). The posterior means of residual correlations (results not shown) between lactations were low for all disorders, 0.06 to 0.31 , -0.04 to $0.14,0.11$ to 0.19 , and -0.05 to 0.19 for $\mathrm{CO}$, $\mathrm{MET}, \mathrm{RP}$, and $\mathrm{SH}$, respectively.

The main challenge with fertility-related disorders is their low frequency and definitions of the traits. In Norway, only veterinary treatments of disease are recorded and, in the analyses, a cow was considered "affected" if she had one or more veterinary treatments for the given disorder during the lactation. For some disorders, such as RP, this covers most of the actual cases of the disorder because it is easy to discover. Other disorders are more challenging and likely include more false negatives, such as $\mathrm{SH}$, for example. Some cases of SH may not be discovered by the farmer and therefore not treated (and consequently, not recorded), or the disorder is discovered but the cow is culled instead of treated. The actual incidence of disease is therefore probably greater than that indicated by the records, valuable information is lost, and genetic analyses may be less accurate. In Tables 2 to 5 , it can be seen that the SD and 95\% HPD intervals for the genetic correlations between lactations were large for MET and SH. This may reflect the low frequency and complexity of these traits, relative to $\mathrm{CO}$ and $\mathrm{RP}$, which have low SD and smaller $95 \%$ HPD intervals.

Genetic correlations between lactations within disorder were positive and moderate to high. Moreover, our results suggest that it is reasonable to assume that $\mathrm{CO}$ in lactations 1 to 5 is genetically the same trait, whereas neither MET nor SH can be considered the same trait across lactations.

\section{ACKNOWLEDGMENTS}

The authors thank the Norwegian Dairy Herd Recording System and the Norwegian Cattle Health
Service (Ås, Norway) for access to data. This work is part of project no 217553/97225 financed by Regionale Forskningsfond, Norway.

\section{REFERENCES}

Heringstad, B. 2010. Genetic analysis of fertility-related diseases and disorders in Norwegian Red cows. J. Dairy Sci. 93:2751-2756.

Heringstad, B., Y. M. Chang, D. Gianola, and G. Klemetsdal. 2005. Genetic analysis of clinical mastitis, milk fever, ketosis, and retained placenta in three lactations of Norwegian Red cows. J. Dairy Sci. 88:3273-3281.

Koeck, A., C. Egger-Danner, C. Fuerst, W. Obritzhauser, and B. Fuerst-Waltl. 2010. Genetic analysis of reproductive disorders and their relationship to fertility and milk yield in Austrian Fleckvieh dual-purpose cows. J. Dairy Sci. 93:2185-2194.

Lin, H. K., P. A. Oltenacu, L. D. van Vleck, H. N. Erb, and R. D. Smith. 1989. Heritabilities of and genetic correlations among six health problems in Holstein cows. J. Dairy Sci. 72:180-186.

Madsen, P., and J. Jensen. 2007. A User's Guide to DMU. A package for analyzing multivariate mixed models. Version 6. Release 4.7. University of Aarhus, Faculty of Agricultural Sciences (DFJ), Dept. Genetics and Biotechnology, Research Centre Foulum, Tjele, Denmark.

Mäntysaari, E. A., Y. T. Gröhn, and R. L. Quaas. 1993. Repeatability and heritability of lactational occurrence of reproductive disorders in dairy cows. Prev. Vet. Med. 17:111-125.

Norwegian Cattle Health Services. 2014. Årsmelding fra helsetjenesten for storfe 2013 (In Norwegian with English tables). Accessed September 2014. http://storfehelse.tine.no/om-oss/\%C3\%A5rsmeldingerog-rapporter $/ \%$ C $3 \%$ A 5 rsmeldinger-helsetjenesten.

Pösö, J., and E. A. Mäntysaari. 1996. Genetic relationship between reproductive disorders, operational days and milk yield. Livest. Prod. Sci. 46:41-48.

Schnitzenlehner, S., A. Essl, and J. Sölkner. 1998. Retained placenta: Estimation of nongenetic effects, heritability and correlations to important traits in cattle. J. Anim. Breed. Genet. 115:467-478.

Smith, B. J. 2003. Bayesian Output Analysis Program (BOA) Version 1.0 User's Manual. http://cran.r-project.org/web/packages/boa/ boa.pdf.

van Dorp, T. E., J. C. M. Dekkers, S. W. Martin, and J. P. T. M Noordhuizen. 1998. Genetic parameters of health disorders, and relationships with 305-day milk yield and conformation traits of registered Holstein cows. J. Dairy Sci. 81:2264-2270.

Zwald, N. R., K. A. Weigel, Y. M. Chang, R. D. Welper, and J. S. Clay. 2004. Genetic selection for health traits using producerrecorded data. I. Incidence rates, heritability estimated and sire breeding values. J. Dairy Sci. 87:4287-4294. 